\title{
Facilitadores e barreiras para a implementação e participação em projetos sociais que envolvem atividades esportivas: os casos dos projetos Vila na Escola e Esporte Ativo
}

CDD. 20.ed. 796.05

\author{
Doralice Lange de SOUZA* \\ Suélen Barboza Eiras de CASTRO* \\ *Universidade Federal \\ Fernando Marinho MEZZADRI*

\section{Resumo}

Este trabalho apresenta os principais facilitadores e barreiras para a implementação de dois projetos sociais e participação de crianças e adolescentes nos mesmos. A pesquisa foi qualitativa e os dados coletados através de entrevistas semiestruturadas com crianças, adolescentes e seus responsáveis; profissionais e voluntários dos projetos. Alguns fatores aparecem ora como facilitadores e ora como barreiras: presença ou ausência de profissionais qualificados e de apoio para o trabalho; quantidade e/ou qualidade das parcerias; nível de consistência no trabalho entre os parceiros; qualidade dos espaços, equipamentos e atividades ofertadas; nivel de envolvimento da comunidade e/ou pais. Os principais facilitadores são: acesso a práticas desportivas; oportunidades de socialização e percepção dos projetos como locais mais seguros do que as ruas. A principal barreira é a falta de segurança no trajeto de casa até o local das atividades e vice-versa. Estes resultados podem contribuir para o desenvolvimento deste e de outros projetos similares.

UnITERMOS: Fatores; Envolvimento; Crianças; Adolescentes.

\section{Introdução}

Vem crescendo no Brasil, desde a década de 80, o número de projetos alternativos e paralelos à educação formal (ZALUAR, 1994), comumente promovidos por instituições como órgãos governamentais, entidades privadas, organizações não-governamentais (ONGs), fundaçôes e institutos empresariais de artistas e atletas, e demais organizações da sociedade civil. Tais projetos têm sido denominados de "projetos sociais" (Barbirato, 2005; Guedes, Davies, Rodrigues \& Santos, 2006; Melo, 2005; Silva, Silveira \& Ávila, 2007; Thomassim, 2006, 2010; ZALUAR, 1994).

Grande parte dos projetos sociais existentes hoje é dedicada a crianças e adolescentes pobres e em situação de "risco social" ou "vulnerabilidade social" e têm como meta ocupar o tempo livre dos mesmos (GONÇALVES, 2003; GuEdEs et al., 2006; Thomassim, 2010) com atividades esportivas, profissionalizantes e/ou complementares à escolarização formal (GonÇALVES, 2003; GuEDES et al., 2006).
Duas perspectivas vêm balizando o debate acadêmico em torno do tema "projetos sociais". A primeira enaltece tais projetos defendendo a posição que os mesmos promovem integração social, combate à violência e à criminalidade, disciplinamento, prevenção do uso de drogas, promoção da saúde e construção de um futuro melhor. Já a segunda vertente os percebe como mecanismos de reprodução do corrente "status quo". Para os defensores desta perspectiva, os projetos sociais só existem porque o Estado não está atendendo efetivamente as necessidades da população. Deste modo, inspirado por correntes neoliberais, o mesmo tem transferido para a sociedade civil a responsabilidade de cuidar de crianças e adolescentes, sem maiores cuidados com a sua educação e preparação para a transformação da realidade em que vivem (THOMASSIM, 2006, 2010; Thomassim, GonZÁLEZ \& FreitAs, 2009).

Embora possamos tecer muitas criticas em relação aos projetos sociais existentes, os mesmos têm cumprido um importante papel social para muitos. 
De acordo com algumas pesquisas, e conforme já apontamos em outro estudo (SouZA, Vialich, EIRAS \& MeZZADRr, 2010), eles são significativos por oferecerem oportunidades de socialização (ABRAMOVAY, 2003, 2006; Marques \& Krug, 2008; Mendes, Peil, Motta, Cardoso, Antunes \& Bucheweitz, 2007; Molina, 2007; VARGAS, 2007; Zaluar, 1994); oferecerem um espaço relativamente seguro quando comparados às ruas (ABRAMOVAY, 2003; 2006; FÉLIX \& Carvilhe, 2008; LeÃo, 2005; Marques \& KRUG, 2008; MENDES et al., 2007; SouZA et al., 2010; VARGAS, 2007; ZALUAR, 1994); proporcionarem acesso a atividades físicas e esportivas (GONÇALVES, 2003; Marques \& Krug, 2008; Mendes et al., 2007; SouZA et al., 2010; THOMASSIM, 2010; VARGAS, 2007; ZALUAR, 1994); tirarem crianças e adolescentes das ruas diminuindo o seu envolvimento com drogas e criminalidade (ABRAMOVAY, 2006; BARBIRATO, 2005; GONÇALVES, 2003; GUEDES et al., 2006; MENDES et al., 2007; Molina, 2007; VARGAS, 2007; ZALUAR, 1994); fornecerem oportunidade de entretenimento e lazer no tempo livre (ABRAMOVAY, 2003, 2006; GONÇALVES, 2003; ZALUAR, 1994); proporcionarem oportunidades

\section{Método}

O trabalho que vamos aqui apresentar é parte de um projeto de pesquisa maior, de natureza qualitativa e exploratória, onde investigamos vários projetos sociais. No caso do presente trabalho, apresentaremos os resultados obtidos a partir de apenas dois dos projetos estudados - o projeto Vila na Escola e Esporte Ativo - tendo como foco questôes que direta ou indiretamente dizem respeito à implementação de atividades e/ou à participação de crianças em atividades físicas ou esportivas.

Os dados foram coletados a partir de entrevistas semi-estruturadas e abertas. No caso do EA, entrevistamos nove mães/responsáveis legais, 52 crianças e adolescentes, e 17 profissionais das instituiçôes envolvidas com o projeto. A coleta se deu de maio a dezembro de 2009. No caso do VE, entrevistamos 10 profissionais, cinco estagiários, três voluntários e 45 crianças e adolescentes que frequentam o VE em cinco diferentes escolas. As entrevistas aconteceram durante os anos letivos de 2008 e 2009. Tendo em vista que a proposta da pesquisa é de cunho exploratório, no caso das crianças e adolescentes, buscamos entrevistar um número equivalente de meninos e meninas de diferentes idades. No caso dos pais, entrevistamos educacionais (GONÇALVES, 2003; LEÃO, 2005; MARQUES \& KRUG, 2008; VARGAS, 2007; ZaLUAR, 1994); e possibilitarem uma perspectiva de profissionalização para os jovens (ABRAMOVAY, 2003; BARBIRATO, 2005; GONÇALVES, 2003; Guedes et al., 2006; MENDES et al., 2007; Thomassim, 2010; Zaluar, 1994).

A despeito da importância de projetos sociais para a vida de um número crescente de crianças e adolescentes, ainda são poucos os estudos, além dos citados acima, que buscam compreender aspectos destes projetos a partir de pesquisas que investiguem a realidade dos mesmos a partir de trabalhos de campo. Acreditando na importância deste tipo de estudos, a pesquisa que aqui apresentaremos visou fazer um levantamento dos principais fatores que interferem com a implementação de projetos sociais e com a participação de crianças e adolescentes nos mesmos, a partir da visão de vários agentes envolvidos com os mesmos. Mais especificamente, estudamos dois projetos que envolvem crianças, adolescentes e atividades de esporte e lazer: projetos "Vila na Escola" (VE) e "Esporte Ativo" (EA). Utilizamos nomes fictícios, a fim de preservar a identidade dos mesmos.

apenas os que tivemos acesso no cotidiano do projeto e/ou que conseguimos agendar um encontro através da administração do projeto. No caso das pessoas que trabalham nos projetos, entrevistamos todos que estavam presentes durante o período de coleta de dados e que concordaram em participar do estudo.

As entrevistas foram realizadas tanto individualmente quanto em pequenos grupos de dois a três participantes. As entrevistas com profissionais, estagiários, voluntários e mães/responsáveis legais duraram entre 30 e 60 minutos. Já as entrevistas com as crianças e adolescentes duraram entre cinco e 15 minutos. Inicialmente realizamos uma entrevista semi-estruturada com os todos os participantes mencionados acima. Após uma análise prévia desta entrevista, nos casos em que percebemos a necessidade de maiores esclarecimentos, realizamos outra entrevista, desta vez aberta, para esclarecermos pontos que necessitavam de maiores explicações. Durante o trabalho de campo, realizamos também algumas observações assistemáticas. $\mathrm{O}$ objetivo das mesmas não era propriamente de coletar dados para respondermos o problema da pesquisa, mas sim o de contextualizar as questões das entrevistas e melhor conhecer a realidade do projeto. 
Gravamos e transcrevemos todas as entrevistas e desenvolvemos as análises com base em procedimentos da grounded theory (STRAus \& CORBIN, 2008). Assim criamos as categorias a partir dos principais temas que emergiram da fala dos sujeitos entrevistados, sem utilizarmos referenciais teóricos "a priori”. Conforme explicam STRAuss e CORBIN (2008), este tipo de procedimento permite que os dados revelem aspectos essenciais da realidade estudada e de temas ainda não tratados pela literatura. Uma vez que trabalhos produzidos a partir desta perspectiva são "enraizados" nos dados, estes tendem a gerar subsídios concretos para intervenção nas realidades estudadas.

Em um primeiro momento da análise, identificamos os temas mais importantes que surgiram das falas de cada um dos sujeitos dos dois projetos estudados. Em um segundo momento, cruzamos os dados dos participantes de cada projeto em específico, comparando estes temas e buscando por similaridades e diferenças. A partir deste procedimento, criamos categorias mais abrangentes para agrupar temas compatíveis. Na medida em que isto foi sendo feito, alocamos tais categorias dentro de três categorias maiores: "barreiras", "facilitadores", e "barreira ou facilitador" para cada um dos projetos em foco. No final contrastamos os resultados dos dois projetos e a partir desta comparação, desenvolvemos o trabalho que vamos apresentar a seguir.

A pesquisa foi aprovada pelo Comitê de Ética da Universidade Federal do Paraná (CAAE: 0012.0.091.000-09) e os participantes da pesquisa e/ou seus responsáveis assinaram o Termo de Consentimento Esclarecido. Para garantir o anonimato dos projetos, não citamos o nome da cidade onde eles ocorrem e nem o nome de instituições que poderiam ser identificadas. Deixamos também de citar as referências completas de algumas das fontes consultadas, que inevitavelmente revelariam a identidade dos projetos. Quando necessário, citamos a fonte de forma genérica. Por exemplo, no caso de manuais dos programas ou fontes eletrônicas com o nome dos programas ou entidades, mencionamos apenas "manual do projeto" ou "site do projeto", respectivamente, e não citamos a referência no final do trabalho. Além disto, utilizamos nomes fictícios não somente para os projetos, mas também para os órgãos responsáveis pelos mesmos e para os participantes da pesquisa.

\section{Resultados e discussão}

\section{O Programa Vida na Escola}

O Programa Vila na Escola (VE) é um projeto social de esporte, lazer e educação criado em 2005 pela Secretaria da Educação do município estudado em parceria técnica com a Organização das Nações Unidas para a Educação, a Ciência e a Cultura (UNESCO). Ele possui parcerias com outras secretarias e órgãos da prefeitura e com associações, instituiçôes de ensino, empresas, igrejas e voluntários que conjuntamente financiam e administram o Programa.

O VE é gratuito, aberto para toda a população e acontece aos sábados e domingos das 09:00 às 17:00 horas em 82 escolas municipais, localizadas em diferentes Regionais da cidade (sub-sedes da prefeitura). O público atendido por este projeto varia tanto em termos de idade (crianças, adolescentes, adultos e idosos), quanto em seu nível sócio-econômico. Segundo o site do projeto, o número de participantes nas atividades do VE até 2009 ultrapassou 1,7 milhões de pessoas (não encontramos nada mais recente sobre os números de participação).

O VE se organiza em torno de cinco eixos principais: esporte e lazer, cultura, saúde, educação

e cidadania, e geração de renda. Enquanto cada um destes eixos possui suas atividades e objetivos específicos, existe um objetivo comum que é o de promover o desenvolvimento sustentável das comunidades, diminuir a vulnerabilidade dos jovens à violência em regiôes que apresentam altos índices de criminalidade, aproximar a comunidade da escola e transformar a escola em um "centro de irradiação do conhecimento". Outro objetivo comum é o de promover "a melhoria na qualidade da educação de crianças, adolescentes e adultos, contribuindo para o ingresso, o regresso e a permanência na escola, bem como a redução dos índices de reprovação escolar" (Manual do Projeto, 2008).

A gestão do Programa é descentralizada e ocorre a partir de quatro instâncias principais: Colegiado de Órgãos, Unidade Gestora do Programa (UGP), Colegiado Regional (COR) e Comitê Local (COL). O Colegiado de Órgãos engloba todos os parceiros públicos e privados do VE e a sua função é a de planejar, acompanhar e validar as ações desenvolvidas no Programa e direcionar os recursos financeiros e materiais para as açôes a serem implementadas. A Unidade Gestora do Programa (UGP) é coordenada 
por um representante da Secretaria Municipal da Educação e a sua função é a de monitorar, avaliar e gerenciar o Programa, promover a viabilização de projetos e fortalecimento da ação intersetorial entre os órgãos e secretarias da PMC. A UGP trabalha diretamente com os coordenadores dos eixos, que por sua vez, devem auxiliar no planejamento de estratégias e diretrizes do Programa de acordo com os objetivos de seu eixo e articular parcerias, integrar diferentes setores, auxiliar na gestão bem como na qualificação dos estagiários de graduação, instrutores e outros agentes do programa que atuam em seu eixo de responsabilidade. O COR é coordenado pelo administrador regional e é composto pelos gerentes regionais da prefeitura municipal, supervisores de eixo, coordenadores de área da Secretaria Municipal de Educação e diretores de escolas participantes do programa. A sua função éa de integrar a ação das secretarias e órgãos da prefeitura com as ações propostas pelo Programa, articular parcerias, gerenciar as atividades desenvolvidas pelos estagiários de graduação e demais agentes envolvidos no Programa, auxiliar na formação do Comitê Local (COL) e promover a troca de experiências entre as escolas de sua abrangência. O Comitê Local atua diretamente na escola e é coordenado por dois professores eleitos da própria escola para atuar no VE. Cabe aos professores coordenadores reunirem-se semanalmente com a comunidade para planejar as atividades que deverão acontecer no final de semana em sua escola. Cabe também a eles identificar os interesses da comunidade, por em prática o plano de ações do Programa, gerenciar os recursos humanos e financeiros destinados ao Programa, articular novas parcerias para o Programa em sua escola, preencher relatórios e controles, orientar os agentes que atuarão no Programa, e avaliar as atividades propostas pelas equipes locais (atendentes, voluntários, estagiários de graduação e instrutores) (Manual do Projeto, 2008).

O eixo de esporte e lazer, foco de nosso estudo, é coordenado pela Secretaria Municipal de Esporte e Lazer (SMEL) em parceria com as Secretarias Municipais da Educação, Saúde e Fundação Cultural. O seu principal objetivo, conforme descrito no manual do projeto, é o de desenvolver a prática de atividade física e esportiva na comunidade, através de ações que promovam educação, inclusão, cooperação e saúde. Alguns exemplos de atividades promovidas por este eixo são o futebol, capoeira, voleibol, artes marciais e tênis de mesa. A oferta de atividades e a duração das mesmas varia, de escola para escola, dependendo da disponibilidade de voluntários e estagiários que se propõem a trabalhar no programa e dependendo da quantia/qualidade de recursos financeiros e humanos que cada unidade do programa, situadas em diferentes escolas, consegue arrecadar através de parcerias. A maioria da mão de obra que atua diretamente no programa se constitui de voluntários e estagiários. A participação nas atividades, em alguns casos, requer inscrição. Em outros casos, os participantes podem se engajar livremente, quando comparecem ao projeto e na hora em que aparecem no projeto, de acordo com a sua vontade.

\section{O Projeto Esporte Ativo}

Inaugurado em 2005, o projeto Esporte Ativo (EA) é promovido pelo Instituto Cidadão do Futuro (ICF) e pela Prefeitura Municipal da Cidade (PMC), através da Fundação de Ação Social (FAS) e da Secretaria Municipal de Esporte e Lazer (SMEL). Ele também possui uma parceria com o Centro de Cultura Italiana (CCI) de uma Universidade privada localizada nos arredores do projeto, e com uma corporação sem fins lucrativos (CO).

O EA se localiza na Vila Amélia, um dos bairros mais pobres da cidade, que enfrenta problemas sociais e ambientais gravíssimos, e onde os habitantes em sua maioria vivem em função da coleta de material reciclável. $\mathrm{O}$ público alvo do projeto são crianças e adolescentes entre oito e 15 anos da Vila, inseridos no Programa de Erradicação do Trabalho Infantil (PETI), um programa do Governo Federal que tem como objetivo a erradicação do trabalho infantil, atendendo a crianças e adolescentes com idade inferior a 16 anos (BrasiL, s/d). Em 2009, quando coletamos os dados, o EA se propunha a atender 160 alunos. No entanto, apenas 90 crianças e adolescentes efetivamente participavam das atividades. Muitos se registravam e não apareciam.

O principal objetivo do EA é o de oferecer uma formação integral e sadia através do esporte e de valores que podem ser desenvolvidos com a sua prática. Este projeto ocorre de segunda a sexta-feira nos períodos da manhã e da tarde. Pela manhã os alunos são atendidos das $08 \mathrm{~h} 30 \mathrm{~min}$ às $11 \mathrm{~h} 30 \mathrm{~min}$ e pela tarde das $13 \mathrm{~h} 30 \mathrm{~min}$ às $16 \mathrm{~h} 30 \mathrm{~min}$. Além de um lanche, o projeto lhes oferece as seguintes atividades: recreação, voleibol, futebol de areia, capoeira, jogos alternativos, futsal, basquete, oficinas, palestras, apoio escolar, italiano, passeios, dança, artesanato e teatro (Site do Projeto, 2009).

Dentre os parceiros do projeto, a corporação $(\mathrm{CO})$ é responsável pela oferta de aulas de dança, artesanato e teatro. A SMEL é responsável pela oferta de basquete e futsal, bem como é responsável pela manutenção da praça onde ocorrem as atividades. O ICF é responsável 
pelo voleibol, futebol de areia e capoeira. Já a FAS é responsável pelas atividades de apoio escolar e recreação. Ela também é responsável pelo acompanhamento e suporte às crianças e adolescentes durante todo o período de projeto. Ou seja, os profissionais desta instituição acompanham os alunos inclusive durante as atividades dos professores das outras entidades parceiras do projeto. Em relação aos profissionais inseridos nas áreas que envolvem o esporte, todos os professores da SMEL e do ICF são professores de educação física formados. Já os profissionais da FAS têm como base de formação o ensino médio. Nenhuma destas instituiçōes conta com o trabalho de voluntários.

Em relação à grade horária do $\mathrm{EA}, \operatorname{logo}$ que as crianças chegam ao projeto se direcionam para a sua

\section{Facilitadores e barreiras}

Em nosso estudo, tal como em outros estudos sobre projetos sociais no Brasil (GONÇALVES, 2003; Marques \& Krug, 2008; Mendes et al., 2007; SouZA et al., 2010; ThOMASSIM, 2010; VArGas, 2007; ZALUAR, 1994), a prática esportiva aparece como o principal atrativo para a participação de crianças e adolescentes em ambos os projetos pesquisados.

Eu venho aqui é para praticar esportes! (João, 11 anos, participante, VE).

Eles gostam, adoram! [...] Eles querem ir quando tá chovendo também! [...] Por que eles, eles jogam, jogam bola, né? [...] Eles gostam assim de vir porque [...] fazem o esportivo, parte esportiva e recreação, né? (Bárbara, mãe/responsável, EA).

A vontade de sociabilizar com outras crianças e adolescentes é outro facilitador para a participação de crianças e adolescentes em projetos sociais (Abramovay, 2003, 2006; MARQUeS \& KRUG, 2008; Mendes et al., 2007; Molina, 2007; VArgas, 2007; ZaLUAR, 1994). Este também é o caso das crianças e adolescentes que participaram de nosso estudo, conforme pode ser observado nas seguintes passagens: É que tem bastante amigo que vem pra cá, né? Que daí não tem como conversar no meio da semana, que todos eles estudam. E aqui, a gente se encontra aqui pra falar, conversar! (Aline, 15 anos, participante, VE).

Porque daí eu brinco, eu não fico sozinha. [...] [Eu venho] pra mim brincar com elas, se não eu vou ficar sozinha! (Jenifer, 11 anos, participante, EA). turma, lancham e escovam os dentes com escova e pasta de dente provenientes do projeto. Em seguida, realizam algumas atividades como pintura, desenho, atividades escolares e jogos de mesa, tudo isto sob a supervisão dos educadores. Após este primeiro momento, os alunos participam de dois blocos de atividade de 50 minutos cada, destinados à atividades esportivas, culturais ou recreativas desenvolvidas pelos parceiros do projeto. Antes de irem para casa, recebem novamente um lanche do projeto.

Gostaríamos de ressaltar que, embora estejamos utilizando o tempo verbal presente para descrever o projeto EA, na fase final de edição deste texto, descobrimos que o projeto encerrou as suas atividades no núcleo que estudamos.

No caso do EA, outro facilitador para a participação das crianças e adolescentes é que este é percebido como um espaço educativo, tanto no que se refere a reforço escolar, quanto em termos de aprendizagem de valores e de desenvolvimento de novos conhecimentos e habilidades.

Aqui aprendem bastante coisa. Aprendem o certo, aprendem o errado, aprendem o que pode fazer e o que não pode fazer, e isso é bom. (Roberta, mãe/responsável, EA).

Eles dão educação, por isso que eu gosto desse projeto. [...] Educação pra nós. [...] Eles passam pra não brigar, pra não, pra não xingar. (Eduardo, 9 anos, participante, EA).

Diversas pesquisas apontam que a participação em projetos sociais é percebida tanto enquanto um meio de educação (GONÇALVES, 2003; LEÃO, 2005; Marques \& Krug, 2008; Zaluar, 1994), quanto de desenvolvimento pessoal (ABRAMOVAY, 2003; VARGAS, 2007) e de promoção de um senso de responsabilidade e de bons comportamentos (Molina, 2007). No caso do VE, no entanto, o fator "educação" não foi mencionado como um atrativo pelos participantes das entrevistas. Aparentemente, para eles, este projeto tem um cunho mais recreacional do que propriamente educativo.

Um dos facilitadores para a participação de crianças e adolescentes no VE é a falta de opçôes de espaços e atividades de lazer na vizinhança deste projeto. Conforme declararam alguns profissionais e várias crianças e adolescentes que entrevistamos, para eles o VE é a sua única alternativa de lazer fora de casa. 
Não tinha nenhum lugar assim que podia ir de graça assim e ainda que é pertinho, né? A melhor coisa que tem pra fazer é vir aqui! (André, 13 anos, participante, VE).

Não temos atividades recreativas, culturais em outros espaços [...]. A comunidade local que não tem acesso aos grandes centros [...], eles frequentam muito aqui a escola né? [...] Por ser perto de casa, né? Por o bairro não oferecer mais nada, [...] nenhum outro atrativo (Mariana, profissional, VE).

Enquanto que para os participantes de alguns projetos sociais (ABRAMOVAY, 2003, 2006), incluindo o VE, a falta de opções de lazer é uma realidade que facilita o envolvimento nas atividades ofertadas, no caso do EA, o excesso de opções de projetos e programas em seu entorno dificulta o engajamento e permanência das crianças no mesmo. Como este projeto se localiza em uma área próxima à várias ONG's e Universidades perto do centro da cidade, esta área é contemplada com a oferta de vários projetos sociais. Consequentemente, ao se deparar com uma variedade de opções, muitas crianças e adolescentes tentam várias delas se matriculando e abandonando os diferentes projetos disponíveis.

A gente [...] gostaria de tirar um pouquinho a possibilidade dele ciscar de projeto pra projeto, porque isso não tem continuidade, e num processo educacional, isso é ruim. Eu acho que isso é uma coisa ruim, quando tem muito projeto. Primeiro porque eles não se integram e competem entre si (Alessandra, profissional ICF, EA).

A qualidade e a diversidade de atividades ofertadas também influenciam os níveis de participação nos dois projetos estudados. No caso do VE, a oferta das atividades oscila e se diferencia de escola para escola, o que em alguns casos prejudica o envolvimento de crianças e adolescentes nas mesmas. Se eu tenho atividade pra ofertar eu tenho público [...]. Se às vezes eu não tenho um público muito grande é porque naquele dia eu não tenho um número de atividades pra ofertar (Cristina, profissional, $\mathrm{VE})$.

Outros colégios têm mais brincadeira, mais coisas pra fazer né? [...] Aqui não. Aqui só tem aqueles brinquedos que você viu ali dentro, e jogar vôlei e jogar futsal! Se fizessem umas brincadeiras, uns bagulhos valendo, aí duvido se não vinha uma galera, né? (Wanderson, 18 anos, participante, VE).

A qualidade e a diversidade de atividades ofertadas pelo EA, principalmente as atividades esportivas, atraem as crianças e adolescentes para o mesmo em detrimento de outros projetos:

O [filho] tava no Exército da Salvação. Daí ele não queria ficar mais lá, porque era preso lá, não podia jogar bola, essas coisas [...]. Então ele quis vir pra cá (Valéria, mãe/responsável, EA).

Porque eu acho esse o mais bom. [...] Porque os outros é só pintar só, e não tem aula assim como nós, que não tem vôlei, não tem futebol, é só pintar só (Rebeca, 11 anos, participante, EA).

Outro atrativo para a participação das crianças e adolescente nos projetos estudados é o fato dos mesmos serem percebidos como uma espécie de "porto seguro" que protege contra supostos perigos e "males das ruas". Alguns dos bairros onde os projetos ocorrem enfrentam sérios problemas relacionados com violência, tráfico de drogas e disputas entre traficantes.

Tinham muitos finais de semana que a gente ficava na rua, né? Sem nada pra fazer aí. Perigoso até acontecer alguma coisa [...]. É melhor ficar aqui do que na rua [...] correndo perigo! (Kelly, 11 anos, participante, VE).

É porque perto da minha casa tem briga de gangue e às vezes dá muito tiroteio e eles ficando aqui eu fico mais tranquila [...]. Então é menos perigo (Roberta, mãe/responsável, EA).

Se por um lado a percepção de projetos sociais como "portos seguros" motiva a participação nos mesmos (Abramovay, 2003, 2006; Félix \& CarviLHE, 2008; LeÃo, 2005; Marques \& KRUG, 2008; Mendes et al., 2007; Souza et al., 2010; VArGaS, 2007; ZaLUAR, 1994), o deslocamento até onde as atividades ocorrem pode se constituir em uma importante barreira para a participação das crianças e adolescentes nas atividades (GONÇALVES, 2003; Melo, 2005; Vianna \& Lovisolo, 2009). No caso de nosso estudo, alguns dos bairros onde acontecem as atividades são violentos e em vários casos, dominados por traficantes. Desta forma, muitos moradores são alijados de seu direito de atravessar de um lado para o outro do bairro onde moram, seja por ordem dos traficantes ou por medo de serem atingidos por balas perdidas. Intimidados por esta situação, muitos não vão até o projeto.

Existe uma divisão de poder dentro da Vila [...] que impede em algum momento que as crianças se locomovam [...]. Então se estabeleceu ali: "Não deixe que o outro passe!", "Passou pra cá eu te mato!” (profissional ICF, EA). 
E se aconteceu no fim de semana, vamos supor, tiroteio assim. Tem mãe que já prende mais, já não deixa que venha. Se o clima tá tenso aí pode contar que vêm bem menos crianças e as que vêm, vêm bem agitadas. [...]. Nessa Vila aqui é a violência que atrapalha, que é o principal fator assim que afeta (profissional FAS, EA).

Por mais que tenha qualquer coisa assim chamativa [...]. Pode fazer o que quiser [...] ninguém vai escolher, né? "Ah eu vou lá me divertir, vou lá ganhar isso ou vou fazer isso, mas eu tô colocando minha vida em risco! Primeiro eu vou defender a minha vida, né?" (mãe/responsável, EA).

Tendo discorrido sobre fatores que interferem com a participação nos projetos estudados, apresentaremos agora os principais facilitadores e barreiras para a implementação dos mesmos. No caso do VE, o principal facilitador além do apoio da Secretaria da Educação do município é o empenho das pessoas que "vestem a camisa" do Projeto.

O grupo é pequeno, mas eu brinco, eu sempre falo, chegou o meu exército, né? [...] As pessoas que estão vestiram bem a camisa, não posso dizer que seja na totalidade, mas é quase que $99 \%$ das pessoas que estão no $\mathrm{VE}$, eles estão mais por amor ao que tão fazendo. A gente não pode ser hipócrita em dizer que, por exemplo, a remuneração não faz diferença, que isso aí seria hipocrisia né? A gente também tem família, tem tudo, mas a grande maioria das pessoas, os que ficaram e os que estão aí trabalhando, vestiram a camisa, arregaçam as mangas e trabalham além (Cristina, profissional, VE).

Se por um lado aqueles que vestem a camisa do projeto impulsionam o desenvolvimento do VE, a falta de verbas para a contratação de um número suficiente de profissionais é uma barreira para a implementação e garantia da qualidade deste projeto. As atividades do VE são desenvolvidas em sua grande maioria por voluntários e estagiários. Como nem todas as comunidades possuem uma cultura de voluntariado, muitas escolas não têm um efetivo suficiente de pessoal para ofertar e desenvolver atividades. Além disto, como os voluntários não possuem um compromisso oficial de trabalho e não recebem pelo que fazem, não raramente os mesmos abandonam o Projeto, prejudicando a continuidade das atividades. Então você consegue às vezes até umas ações maiores de um parceiro lá, corte de cabelo, unha decorada. Aí faz todo aquele trabalho de divulgação, chega na sexta-feira, quatro horas da tarde, ele te avisa que não vai poder ir (Vera, profissional, VE).
Ele [o voluntário] arruma um emprego, por exemplo, ele já não vem [...]. Às vezes você tenta algum curso assim, a pessoa começa a dar curso lá de crochê, de coisa assim. E aí chega um belo dia o povo tá aí esperando e cadê? Você vai lá, liga: "Escute o que quê aconteceu?" "Ah encheu minha casa de visita, tô com a casa cheia de visita, não posso sair”. É voluntário, você vai fazer o que? (Cristina, profissional, VE).

Outro problema da dependência de voluntários para o funcionamento do VE é que muitos não possuem formação adequada na área pedagógica. Durante a nossa coleta de dados observamos casos onde os mesmos disseminavam práticas inapropriadas de forma acrítica. Vimos, por exemplo, um voluntário ensinando crianças pequenas a dançarem coreografias de músicas com um forte cunho erótico, comuns na mídia. Conforme aponta PACHECO (2006, p.209), a falta de preparo pode levar trabalhadores a reproduzir práticas "atravessadas pela indústria cultural". Outros exemplos de situações problemáticas que observamos foram a exclusão de crianças e adolescentes menos habilidosas de determinadas atividades. Esta situação foi consistentemente observada no caso do futebol. Vejamos, por exemplo, alguns comentários sobre esta situação feito por algumas meninas:

A gente tava querendo participar e não deixaram. Falaram que era muito forte para a gente e a gente não podia [...]. Aí eles convidam os meninos. Quando vai menina, às vezes, falam que não pode (Adriana, 12 anos, VE).

Menina assim, eles pegam bem pouca, porque o futebol é muito forte, né? Aí eles convidam pouca menina, mas piá eles convidam bastante! [...] Às vezes as meninas querem e eles dizem que não pode (Julia, 11 anos, VE).

Conforme apontaram alguns de nossos entrevistados, os voluntários não deveriam dirigir as atividades, mas sim, complementar o trabalho de profissionais devidamente capacitados para o trabalho.

Então a gente precisa, por exemplo, voluntários que venham [fazer uma] colaboração com os profissionais que estão já atuando. Exemplo: um professor, um bom professor que desenvolva um programa de futebol, né? É válido um voluntário chegar e fazer parceria com esse professor e ajudar ele diretamente nas atividades, né? Orientando os alunos, ajudando no treinamento, etc. e tal. Agora, eu sou contra a uma pessoa, extremamente leiga, vir fazer uma atividade que ela nem sequer realmente conhece, né? (Fabio, profissional, VE). 
O voluntariado [...], ele deveria ser assim uma soma, uma coisa a mais e não a base (Cristina, profissional, VE).

Da mesma forma que os voluntários, grande parte dos estagiários que trabalham no VE também não estão devidamente preparados. Durante as entrevistas, eles admitiram fragilidades e alegaram que se sentem sem apoio para o desenvolvimento de um bom trabalho.

Não tinha o apoio [...] pra direcionar uma atividade [...] É muito fácil um estagiário chegar lá, soltar uma bola, sentar e ficar esperando o sábado passar, assim sabe? [...]. Não tem essa organização de eles verem o que você tá fazendo nem o que você vai fazer [...]. Então, a gente ficava lá [...]. Dez horas depois, o colégio pega fogo e você não sabe o que fazer (Mauro, estagiário, VE).

Enquanto os estagiários reclamaram da falta de comprometimento de seus coordenadores, os seus coordenadores, por sua vez, alegaram se sentir sem condiçôes de desenvolver um bom trabalho por falta de recursos humanos e materiais.

O pessoal pode chegar e falar: "Pô, a escola é ruim por causa do coordenador!” Só que não é. Eu não consigo fazer coisas que eu não tenho recursos pra fazer, não tenho material humano pra fazer (Maurício, profissional, VE).

A gente pena bastante com esses estagiários muito jovens, né? Esses principalmente [...] de primeiro semestre. A gente pena muito com eles porque [...] ele tá cru ainda, ainda tá aprendendo o que é a profissão dele, né? (Valdir, profissional, VE).

Outro problema relacionado com a questão dos estagiários é a alta rotatividade dos mesmos.

É uma dificuldade [...] a rotatividade de estagiário

[...]. A gente já teve vários estagiários bons que desenvolveram um excelente trabalho. A comunidade veio, né? E quando esse estagiário sai, quando ele deixa de vir, aí a comunidade fica sem a oferta daquela atividade (Paula, profissional, VE).

A alta rotatividade de trabalhadores no projeto compromete tanto a continuidade das atividades quanto também a possibilidade de fortalecimento de laços entre professores e alunos. Isto tudo, por sua vez, repercute na qualidade do trabalho desenvolvido.

A carência de profissionais e/ou de falta de capacitação para o trabalho é um problema constante em projetos sociais, tal como foi constatado, por exemplo, nos casos dos programas "Abrindo Espaços" (ABramovaY, 2003) e "Escola Aberta” (LEÃo, 2005). Já no caso do EA, este não depende de voluntários e estagiários para desenvolver as atividades.
Este projeto, no entanto, enfrenta problemas de outra natureza: falta de profissionais qualificados em determinadas áreas de conhecimento e falta de apoio para o desenvolvimento do trabalho.

Mas é uma pena que a gente não tem um pedagogo aqui [...].Como eu não tenho formação nessa área e como eu nunca tive experiência nessa área, eu tenho muita dificuldade de aplicar alguma coisa. Eu não sei exatamente o que aplicar, se eu tô aplicando certo. Então eu fico restrita (Neide, profissional FAS, EA).

O PETI, ele poderia nos dar subsídios de profissionais mais eficazes. Por exemplo, que tivesse pedagogos, né, que tivesse dentro aqui da nossa praça, né? Uma assistente social, que tivesse uma psicóloga [...]. As crianças que precisariam ter esses profissionais ali junto deles pra poder tá fazendo um trabalho mais [pausa] desenvolver um trabalho melhor. Porque os educadores, eles têm boa vontade, mas nós não somos profissionais pra poder tá lidando com algumas situações (Daniela, profissional FAS, EA).

Enquanto os profissionais da FAS reclamam de suas condições de trabalho, os profissionais do ICF elogiam as mesmas. Segundo os mesmos, eles contam com cursos de capacitação e reuniões periódicas para planejar e discutir o seu trabalho. Além disto, possuem o apoio da psicóloga do Instituto para auxiliá-los a lidar com as dificuldades que encontram em seu cotidiano.

O que me deixa mais feliz de estar aqui é todo esse apoio que a gente tem [...]. A gente tem sempre um reforço, a gente pode tirar as dúvidas com os outros professores [...]. Também o apoio que a gente tem, né? Através da psicologia do esporte que ajuda bastante pra até você se entender durante a aula, saber como lidar com determinados comportamentos que cada aluno tem (Isabela, profissional ICF, EA).

As parcerias ora aparecem como facilitadores e ora como barreiras para a implementação dos projetos pesquisados. No caso do VE, este depende de parcerias e voluntários para o seu funcionamento. Em 2009 contava com 173 parcerias formadas por empresas (43\%), associações de moradores e clubes de mães (13\%), instituições religiosas (12\%), ONG's (11\%), grupos artísticos (7\%), instituições de ensino superior (6\%), jornais (5\%) e outras entidades (3\%). Embora o número de parceiros no projeto esteja aumentando, existe uma disparidade no número de parcerias entre as diferentes escolas. Por exemplo, enquanto em 2009 um dos núcleos regionais possuía 39 parceiros locais que atendem escolas vinculadas ao VE e pertencentes 
a este núcleo, outro núcleo regional possui apenas um parceiro local que atendia apenas uma das escolas deste núcleo (Site do Projeto, 2009).

Então a gente sabe que existem bastantes parceiros por aí, mas na nossa comunidade têm poucos, muito poucos. Então a gente só conta mesmo com as instituições da prefeitura, né? [...]. A comunidade aqui não tem condiçôes de ter parcerias (Regina, profissional, VE).

Diversos fatores interferem com a formação de parcerias, como por exemplo, a localização da escola, a presença de comércio e/ou empresas em suas proximidades e a capacidade da escola de atrair parceiros. Estes fatores, entre outros, influenciam a captação de recursos financeiros e humanos. As parcerias são fundamentais para a consolidação e diversificação das atividades desenvolvidas pelo VE. Contudo, conforme aponta PACHeCo (2006), estas, se não mediadas, podem levar a uma espécie de privatização do espaço público da escola, que, sem um cuidado maior, pode passar a atender apenas a interesses de pequenos grupos da comunidade. Alguns exemplos disto podem ser verificados em casos onde grupos esportivos organizados "tomam posse" de quadras esportivas para treinos e campeonatos.

Lá é reservado pra futebol e pra vôlei. [...] Pra time treinar. Porque às vezes vai fazer, querer fazer essas coisas assim e daí não pode porque eles tão treinando, os times, essas coisas, daí não pode! [...] Aí é ruim porque só porque eles que tem time, eles tem que ficar treinando lá (Flávia, 12 anos, participante, VE).

Grupos mais organizados tendem a se apropriar mais facilmente dos espaços escolares do que membros da comunidade menos organizados. Desta forma, os gestores destes espaços necessitam estabelecer formas de controle social para que os últimos não se tornem "reféns" de tais grupos (PACHECO, 2006).

No caso do projeto EA, embora este não dependa da constituição de parcerias para acontecer - as parcerias já estão bem estabelecidas - o trabalho entre os parceiros carece de mais integração e consistência. Observamos, por exemplo, que enquanto os profissionais do ICF estão preocupados com a aprendizagem de determinados valores e habilidades esportivas, a preocupação dos profissionais da FAS parece estar mais voltada ao acolhimento e cuidados com as crianças do que com a sua educação propriamente dita. Desta forma, as suas práticas não raramente entram em choque. As seguintes passagens de entrevistas ilustram este ponto:

Eu acho que elas [profissionais da FAS] deveriam ter um pulso mais firme. Muitas delas também criam um afeto com eles. Aí você tira pra eles terem um castigo. [Daí elas tão] ali com eles sentados no colo, fazendo cafuné. Daí já não funcionou [...]. Às vezes a gente dá uma lição, por exemplo, "Ó você sai da aula e fica ali, fica ali junto com o educador e vai fazer alguma coisa!". Aí a educadora fica brincando com ele [...]. A gente fala uma coisa, quer que tenha aquela punição, mas talvez não foi uma punição [...]. Eu dou a punição, "Fica aí!", ”Sai!". E tudo que ele queria era sair pra jogar bola e conseguiu sair pra jogar bola (Julia, profissional ICF, EA).

Eles tiram para fora as crianças que não se comportam bem. Nós não. Não queremos tirar, pois enquanto o mundo todo fecha a porta para eles, precisamos manter as nossas abertas (Fábia, profissional FAS, EA).

Outro fator que interfere com o desenvolvimento de projetos sociais são as condiçôes dos espaços e equipamentos para o desenvolvimento das atividades (Abramovay, 2006; Leão, 2005). No caso do $\mathrm{VE}$, estas condições variam drasticamente. Enquanto algumas escolas possuem uma boa infra-estrutura (ex. quadras cobertas e materiais esportivos de boa qualidade), outras não possuem nem espaços e nem equipamentos adequados. No caso do EA, embora os profissionais das diferentes instituições que coordenam o projeto contem com os mesmos espaços para o desenvolvimento das atividades propostas, a disponibilidade de materiais para o seu trabalho varia drasticamente. Enquanto o pessoal da FAS reclama da falta de materiais, os profissionais do ICF elogiam a disponibilidade e qualidade dos materiais disponibilizados para o seu trabalho.

A "cultura de participação" da comunidade e/ou dos pais/responsáveis pelas crianças e adolescentes é outro fator que interfere com a implementação de programas sociais. Os nossos dados revelam que no caso do VE, as escolas que já cediam seu espaço para a prática de esportes pela comunidade nos finais de semana antes da implementação do Projeto possuem um grau de maior envolvimento da comunidade nas atividades do que escolas onde não existia esta tradição.

Nós já tínhamos um trabalho na comunidade desde que a escola existe e dai foi evoluindo. Nós sempre fazíamos um empréstimo do espaço externo da escola para grupos da comunidade que vão jogar futebol, voleibol, fazer essas atividades. Então no período do final de semana eles vinham à escola, entravam na escola, para usar o espaço externo, especificamente a cancha. Tem outras escolas que o povo não aparece (Dirce, profissional, VE). 
Os nossos dados também demonstram que as comunidades que são mais politicamente organizadas tendem a ser mais participativas tanto no planejamento das atividades quanto em seu envolvimento com as mesmas.

[Em] muitas escolas assim, a comunidade não sabe que pode opinar. Não têm essa visão de participação [...]. Têm todo um ranço de sociedade paternalista e assistencialista de a pessoa "não, é Programa da prefeitura, vamos esperar pra ver o quê que eles têm pra fazer”. E não se posicionam enquanto agentes participativos pro projeto (Jeferson, profissional, VE).

No caso do EA, mais especificamente, este não prevê a participação da comunidade na gestão do projeto. Ele requer apenas que os pais participem de reunióes periódicas. A participação dos pais nestas reuniōes, no entanto, é pequena, seja por falta de tempo ou de interesse. De acordo com depoimentos de alguns profissionais entrevistados, as crianças e adolescentes cujos pais/responsáveis participam mais frequentemente destas reuniões tendem a ser mais assíduas no projeto.

Concluindo, os principais facilitadores para a participação de crianças e adolescentes em ambos os projetos são: acesso à pratica desportiva; possibilidade de socialização e o fato dos projetos serem percebidos como uma espécie de "porto seguro" que protege os menores de supostos perigos das ruas. A principal barreira para a participação em ambos os projetos é a falta de segurança no trajeto até o local das atividades. Existem também fatores que ora se constituem como facilitadores e ora como barreiras para a participação dependendo do projeto ou localidade onde o projeto ocorre: natureza e qualidade das atividades ofertadas, e falta ou excesso de opçóes de lazer no entorno de onde acontecem os projetos. Em relação aos fatores que interferem com a implementação dos projetos, os principais facilitadores e/ou barreiras são: presença ou ausência de profissionais qualificados e de apoio para o trabalho dos mesmos; qualidade das parcerias formadas e consistência no trabalho desenvolvido pelos diferentes parceiros; envolvimento ou falta de envolvimento da comunidade e/ou pais nos projetos; disponibilidade e qualidade dos espaços e equipamentos.

Com base nos dados discutidos até então, concluímos que para uma maior participação de crianças e adolescentes tanto no VE quanto no EA, necessita-se garantir a segurança no trajeto de casa até os locais onde ocorrem as atividades. Já os principais requisitos para que se possa garantir a qualidade das ações desenvolvidas são: 1) a contratação de profissionais qualificados, ou melhor qualificados, para trabalharem nos projetos; e 2) a oferta de boas condiçôes de trabalho para todos envolvidos no desenvolvimento das atividades (ex. disponibilidade de espaços e equipamentos para todos os núcleos que hospedam os projetos e apoio para o desenvolvimento do trabalho dos profissionais atuantes). Esperamos que os resultados desta pesquisa possam servir como subsídios para o aprimoramento dos projetos estudados e para o desenvolvimento de outros similares, buscando a otimização dos facilitadores e a minimização das barreiras que interferem com a implementação dos projetos e participação de crianças e adolescentes nos mesmos.

\title{
Nota
}

Esta pesquisa recebeu o apoio financeiro dos Programas Licenciar e de Iniciação Científica da UFPR e do Ministério do Esporte, via Rede CEDES.

\begin{abstract}
Facilitators and barriers to the implementation and participation in social projects that involve sport activities: the case of Village School Program and of the Active Sport projects

This paper presents the main facilitators and barriers for the implementation of two social projects and for the participation of children in them. The research was qualitative and data were collected through semi-structured interviews with children and their parents/guardians; professionals and volunteers of the projects. Some factors are sometimes facilitators or barriers to implementation: the presence or
\end{abstract}


absence of qualified professionals and of support for their work, quantity and/or quality of partnerships; level of consistency in the work of the partners, quantity and quality of space and equipment available; level of involvement of the community and/or parents. The main facilitators for participation are: access to sport activities, socialization opportunities, and perception of the projects as saver than streets. The main barrier is lack of security in the passage to and from the projects. The results of this research can contribute to the improved of these and other similar projects.

UNITERMS: Factors; Involvement; Children; Adolescents.

\section{Resumen}

Facilitadores y barreras para la implementación y participación en proyectos sociales que involucren actividades deportivas: el caso de los proyectos Barrio en la Escuela y Deporte Activo

Este trabajo presenta los principales facilitadores y barreras para la implementación y participación de niños y adolescentes en proyectos sociales. La investigación fue cualitativa y datos recogidos a través de entrevistas estructuradas con niños, adolescentes, responsables; profesionales y voluntarios de los proyectos. Los siguientes factores aparecen algunas veces como facilitadores, otras como barreras para la implementación: presencia o ausencia de profesionales calificados y apoyo para su trabajo; cantidad y/o calidad de asociaciones; consistencia del trabajo realizado por asociados; nivel de participación de la comunidad y/o padres; calidad de los espacios, instalaciones y actividades. Los principales facilitadores para participación son: acceso a prácticas deportivas; socialización y el hecho de proyectos ser vistos como lugares más seguros que las calles. La principal barrera es falta de seguridad camino de casa al local de actividades y viceversa. Los resultados de este estudio proporcionan apoyo para desarrollo de estos proyectos y otros similares.

Palabras Clave: Factores; Participación; Niños; Adolescentes.

\section{Referências}

ABRAMOVAY, M. Abrindo espaços na Bahia: avaliação do programa. Brasília: UNESCO/Observatório de Violências nas Escolas/Universidade Católica de Brasília/UNIRIO, 2003.

Fazendo a diferença: Projeto Escola Aberta para a Cidadania no Estado do Rio Grande do Sul. Brasília: UNESCO/Secretaria da Educação do Rio Grande do Sul, 2006. Disponível em: <http://unesdoc.unesco.org/ images/0014/001455/145551 por.pdf>. Acesso em: 12 fev. 2009.

BARBIRATO, F.R. A socialização no contexto de projetos esportivos: um estudo de caso na Fundação Gol de Letra. 147 f. Dissertação (Mestrado em Educação) - Centro de Estudos Sociais Aplicados, Universidade Federal Fluminense, Niterói, 2005. Disponível em: <http://www.uff.br/pos_educacao/joomla/images/stories/Teses/fernandab.pdf>. Acesso em: 23 jun. 2010. BRASIL. Ministério do desenvolvimento social e combate à fome. Programa de erradicação do trabalho infantil (PETI). s/d. Disponível em: <http://www.mds.gov.br/programas/rede-suas/protecao-social-especial/programa-de-erradicacao-dotrabalho-infantil-peti>. Acesso em: 10 jun. 2009.

FÉLIX, C.M.R.; CARVILHE, M. Avaliação de impacto do Programa Comunidade Escola: relatório de pesquisa da etapa qualitativa. Curitiba: Prefeitura Municipal de Curitiba, 2008. Disponível em: <http://www.cidadedoconhecimento. org.br/cidadedoconhecimento/index.php?portal=527\&opTpl=down>. Acesso em: 10 set. 2008.

GONÇALVES, M.A.R. A Vila Olímpica da Verde-e-Rosa. Rio de Janeiro: FGV, 2003. (Violência, Cultura e Poder). GUEDES, S.L.; DAVIES; J.B.; RODRIGUES, M.A.; SANTOS, R.M. Projetos sociais esportivos: notas de pesquisa. 2006. In: ENCONTRO REGIONAL DE HISTÓRIA, 12., 2006, Niterói. Anais... Rio de Janeiro: ANPUH, 2006. p.92. Disponível em: <http://www.rj.anpuh.org/Anais/2006/conferencias/Simoni\%20LGuedes, \%20Julio\%20Davies, \%20 Michelle\%20ARodrigues\%20e\%20Rafael\%20MSantos.pdf>. Acesso em: 23 abr. 2009. 
LEÃO, J.A.C. Consideraçóes sobre o projeto escola aberta: perspectivas para uma agenda de lazer. 2005. Dissertação (Mestrado) - Fundação Joaquim Nabuco, Instituto de Formação e Desenvolvimento Profissional. Disponível em: <http:// www.campus12.uneb.br/texto/artigos/escola_aberta.pdf>. Acesso em: 10 maio 2009.

MARQUES, M.N.; KRUG, H.N. As contribuiçóes do Programa Segundo Tempo para os discentes de uma escola estadual de Santa Maria (RS): um estudo de caso fenomenológico. Lecturas, Educación Física y Deportes: Revista Digital, Buenos Aires, v.13, n.124, 2008. Disponível em: <http://www.efdeportes.com/efd124/as-contribuicoes-do-programa-segundo-tempo.htm>. Acesso em: 08 jun. 2009. MELO, M.P. Esporte e juventude pobre: políticas públicas de lazer na Vila Olímpica da Maré. Campinas: Autores Associados, 2005. (Coleção educação física e esportes)

MENDES, V.R.; PEIL, L.M.; MOTTA, J.A. CARDOSO, L.P.; ANTUNES, N.S.; BUCHEWEITZ, R. Como os pais percebem a participação dos filhos no Programa Segundo Tempo. In: CONGRESSO BRASILEIRO DE CIÊNCIAS DO ESPORTE, 15. Pernambuco. Anais... Recife: CBCE, 2007. Disponível em: <http://www.cbce.org.br/cd/resumos/265.pdf>. Acesso em: 23 abr. 2009. MOLINA, R.K. Políticas de esporte e projetos sociais: impactos nos processos de subjetivação dos jovens. In: CONGRESSO BRASILEIRO DE CIÊNCIAS DO ESPORTE, 15., Pernambuco. Anais... Recife: CBCE, 2007. Disponível em: <http:// www.cbce.org.br/cd/resumos/278.pdf>. Acesso em: 23 abr. 2009.

PACHECO, R.T.B. A escola pública e o lazer: impasses e perspectivas. In: PADILHA, V. (Org.). Dialética do lazer. São Paulo: Cortez, 2006.

SILVA, M.R.; SILVEIRA, J.; ÁVILA, A.B. Políticas públicas para o esporte: cidadania e inclusão social. In: SILVA, M.R. (Org.). Esporte, educação, estado e sociedade. Chapecó: Argos, 2007. p.105-76.

SOUZA, D.L.; VIALICH A.L.; EIRAS, S.B.; MEZZADRI, F.M. Determinantes para a implementação de um projeto social. Motriz, Rio Claro, v.16, n.3, 2010, p.689-700.

STRAUSS, A.; CORBIN, J. Pesquisa qualitativa: técnicas e procedimentos para o desenvolvimento de teoria fundamentada. 2. ed. Porto Alegre: Porto Alegre, 2008.

THOMASSIM, L.E.C. Uma alternativa metodológica para a análise dos projetos sociais esportivos. 2006. In: ENAREL, 28., 2006, Curitiba. Anais... Curitiba: PUCPR, 2006.

O “público-alvo" nos bastidores da política: um estudo sobre o cotidiano de crianças e adolescentes que participam de projetos sociais esportivos. 296 f. Tese (Doutorado em Ciências do Movimento Humano) - Programa de Pós-Graduação em Ciência do Movimento Humano, Universidade Federal do rio Grande do Sul, 2010.

THOMASSIM, L.E.C.; GONZÁLEZ, F.J.; FREITAS, M. V. Desigualdades sociais e invisibilidade de classe: projetos sociais e a criança como "problema social". In: CONGRESSO BRASILEIRO DE CIÊNCIAS DO ESPORTE, 26., Salvador. Anais... Salvador: CBCE, 2009. Disponível em: <http://cbce.tempsite.ws/congressos/index.php/CONBRACE/ XVI/paper/view/1445/788>. Acesso em: 28 set. 2009.

VARGAS, L.S. Esporte, interação e inclusão social: um estudo etnográfico do "Projeto Esporte Clube Cidadão". 119 f. Dissertação (Mestrado) - Departamento de Ciências Sociais Aplicadas, Universidade do Vale do Rio dos Sino, São Leopoldo, 2007. Disponível em: <http://bdtd.unisinos.br/tde_busca/arquivo.php?.codArquivo=434>. Acesso em: 23 abr. 2009. VIANNA, J.A.; LOVISOLO, H.R. Projetos de inclusão social através do esporte: notas sobre a avaliação. Movimento, Porto Alegre, v.15, n.3, p.145-62, 2009. Disponível em: <http://www.seer.ufrgs.br/index.php/Movimento/article/ view/5190/5583>. Acesso em: 23 set. 2009.

ZALUAR, A. Cidadãos não vão ao paraíso. São Paulo: Escuta, 1994.

ENDEREÇO

Doralice Lange de Souza

Av. Senador Salgado Filho, 1800 - casa 11 81510-001 - Curitiba - PR - BRASIL e-mail: dora@ufpr.br
Recebido para publicação: 05/ 08/2011

Revisado: 05/ 03/2012

Aceito: 18/05/2012 